\title{
Electromagnetic field investigation on different cancer cell lines
}

\author{
Nenad Filipovic ${ }^{1,2,3^{*}}$, Tijana Djukic ${ }^{1,3}$, Milos Radovic ${ }^{1,3}$, Danijela Cvetkovic ${ }^{4}$, Milena Curcic ${ }^{4}$, Snezana Markovic ${ }^{4}$, \\ Aleksandar Peulic ${ }^{1}$ and Branislav Jeremic ${ }^{3,5}$
}

\begin{abstract}
Background: There is a strong interest in the investigation of extremely low frequency Electromagnetic Fields (EMF) in the clinic. While evidence about anticancer effects exists, the mechanism explaining this effect is still unknown.

Methods: We investigated in vitro, and with computer simulation, the influence of a $50 \mathrm{~Hz}$ EMF on three cancer cell lines: breast cancer MDA-MB-231, and colon cancer SW-480 and HCT-116. After $24 \mathrm{~h}$ preincubation, cells were exposed to 50 Hz extremely low frequency (ELF) radiofrequency EMF using in vitro exposure systems for 24 and $72 \mathrm{~h}$. A computer reaction-diffusion model with the net rate of cell proliferation and effect of EMF in time was developed. The fitting procedure for estimation of the computer model parameters was implemented.

Results: Experimental results clearly showed disintegration of cells treated with a $50 \mathrm{~Hz} E M F$, compared to untreated control cells. A large percentage of treated cells resulted in increased early apoptosis after $24 \mathrm{~h}$ and $72 \mathrm{~h}$, compared to the controls. Computer model have shown good comparison with experimental data.

Conclusion: Using EMF at specific frequencies may represent a new approach in controlling the growth of cancer cells, while computer modelling could be used to predict such effects and make optimisation for complex experimental design. Further studies are required before testing this approach in humans.
\end{abstract}

Keywords: Electromagnetic fields, Computer simulation, Breast cancer, Colon cancer

\section{Background}

Alternating electric fields have shown a wide range of effects on living tissues. Depending on frequencies, their activity ranged from stimulating excitable tissues such as nerve, muscle or heart [1,2], through stimulating bone growth and accelerating fracture healing [3] to using it for diathermy and radiofrequency tumour ablation [4]. Intermediate-frequency electric fields $(>10 \mathrm{KHz}$ to $\mathrm{MHz})$ were mostly considered as having no overt biological effect [5] and, hence, medical application, though several non-thermal cellular effects have been observed [6-8].

The last decade also brought a number of in vitro and in vivo studies which documented the anticancer effects of alternating electric fields [9-11], including low-intensity intermediate frequency $(100-300 \mathrm{KHz})$ alternating electric fields, as well as amplitude-modulated electromagnetic

\footnotetext{
* Correspondence: fica@kg.ac.rs

${ }^{1}$ Faculty of Engineering, University of Kragujevac, Sestre Janjica 6, 34000 Kragujevac, Serbia

${ }^{2}$ Harvard University, Boston, USA

Full list of author information is available at the end of the article
}

fields (EMF) of somewhat lower frequencies $(0.1 \mathrm{~Hz}$ to $114 \mathrm{KHz}$ ) [12]. As recently summarized [13] Zimmermann, 2013), these studies showed that anticancer effects were achieved at specific (for the cancer cell type) modulation frequencies and demonstrated proliferative inhibition and mitotic spindle disruption following exposure to alternating electric fields $[10,11]$. Furthermore, bridging important aspects of apoptosis $[14,15]$ with extremely low frequency (ELF) pulsed-gradient magnetic fields, Zhang et al [16] showed that the latter can not only induce it, but may also block the development of neovascularization required for tumour supply. Harris et al [17] have been shown that ELF might be capable of exacerbating an inherent or induced genetic instability by reducing or attenuating the stringency of the late-cycle (G2) checkpoint. Cameron et al [18] found that mice received either gamma irradiation IR or EMF therapy had significantly fewer lung metastatic sites and slower tumor growth than did untreated mice. Also they did not find harmful side effects with EMF. Initial clinical results in various tumour entities/sites (recurrent 
glioblastoma multiforme, hepatocellular carcinomas, breast carcinomas) were encouraging $[10,12,19]$.

On the other side, computer models have the common aim of predicting certain features of tumour growth in the hope of finding new ways to combat cancer. The golden aim of computer modelling is to create a model which yields reproducible and accurate predictions, the effects of different genetic, epigenetic and environmental changes, as well as the impact of therapeutically targeting different aspects of the tumour. In order to make a clinically relevant cancer simulation tool that accurately predicts in vivo tumour growth dynamics, shape and spread throughout an organ, computational models must consider the location of a tumour within the organ, and the physical constraints placed on growth by that organ. Treatment plans based on the use of such computer modelling and simulation processes will require rigorous validation studies and regulatory approvals before integration into the clinical practice [20].

Based on these premises, we investigated the influence of EMF at specific frequencies on three cell lines in an in vitro setting.

\section{Methods}

\section{Experimental design for electromagnetic field}

The experiment is performed using the two coils with 11300 copper windings each. The coils are appointed in vertical position and connected in parallel to the alternate current source as it has been shown in the Figure $1 \mathrm{~A}, \mathrm{~B}$. According to right hand screw rule the achieved connection enable superposition of magnetic field from both coils and maximum intensity in the center between coils.

The VC2002 function signal generator is used with output voltage of $9.1 \mathrm{~V}$ peak to peak values and frequency of $50 \mathrm{~Hz}$ and current amplifier up to 1A. The applied field is with frequency of $50 \mathrm{~Hz}$ with RMS value of $10 \mathrm{mT}$. Environmental background magnetic field is several $\mu \mathrm{T}$ order so it can be neglected.

\section{Cell preparation and culturing}

The breast cancer cell line, MDA-MB-231, and colon cancer cell lines, SW480 and HCT-116, were obtained from the American Tissue Culture Collection (Manassas, VA, USA). Cells were propagated and maintained in Dulbecco's Modified Eagle Medium (DMEM), (Gibco, USA), supplemented with $10 \%$ foetal bovine serum (PAA) and antibiotics (100 IU/mL penicillin and $100 \mu \mathrm{g} / \mathrm{mL}$ streptomycin). Cells were grown in $75 \mathrm{~cm}^{2}$ culture flasks containing $15 \mathrm{ml}$ DMEM. After a few passages cells were seeded in a 96-well plate $\left(10^{4}\right.$ cells per well) and cultured in a humidified atmosphere of $5 \% \mathrm{CO}_{2}$ at $37^{\circ} \mathrm{C}$. All studies used cells at 70 to $80 \%$ confluence.

\section{Cell viability assay (MTT assay)}

Cell viability was determined by MTT assay [21]. After $24 \mathrm{~h}$ incubation cells were exposed to $50 \mathrm{~Hz}$ EMF using in vitro exposure systems, for $24 \mathrm{~h}$ and $72 \mathrm{~h}$ [21-23]. Untreated cells served as the control. At the end of the period of exposure, MTT (final concentration $5 \mathrm{mg} / \mathrm{ml}$ in PBS) was added to each well, and the multiwell plate incubated at $37^{\circ} \mathrm{C}$ in $5 \% \mathrm{CO}_{2}$ for $2 \mathrm{~h}$. The coloured crystals of produced formazan were dissolved in dimethyl sulfoxide (DMSO) (Sigma, USA). The absorbance was measured at $550 \mathrm{~nm}$. Cell proliferation was calculated as the ratio of the absorbance of the treated group, divided by the absorbance of the control group, multiplied by 100 , to give percentage of proliferation [21].

\section{Fluorescence microscopic analysis of cell death with} acridine orange/ethidium bromide (AO/EB) double staining For analysis of cell death, we used fluorescent assays $\mathrm{AO} / \mathrm{EB}$ double staining [22]. AO is taken up by both viable and nonviable cells and emits green fluorescence when it bonds with double stranded nucleic acid (DNA), or red fluorescence if bound to single stranded nucleic acid (RNA). Ethidium Bromide is taken up only by nonviable cells and emits red fluorescence by intercalation with DNA. We distinguished four types of cells according to the fluorescence emission and the morphological aspect of chromatin condensation in the stained nuclei. Viable cells have uniform bright green nuclei with an organized structure. Early apoptotic cells have green nuclei, but perinuclear chromatin condensation is visible as bright green patches or fragments. Late apoptotic cells have orange to red nuclei with condensed or fragmented chromatin. Necrotic cells have uniformly orange to red nuclei with condensed structure. $20 \mu \mathrm{l}$ of dye mixture $(10 \mu \mathrm{g} / \mathrm{ml} \mathrm{AO}$ and $10 \mu \mathrm{g} / \mathrm{ml} \mathrm{EB}$ in distilled water) was mixed with $100 \mu \mathrm{l}$ cell suspension (10 000 cells $/ \mathrm{ml}$ ) in a 96-well plate. After incubation times ( $24 \mathrm{~h}$ and $72 \mathrm{~h}$ ) the suspension was immediately examined and viewed using a Nikon inverted fluorescent microscope (Ti-Eclipse) at 400x magnification. Untreated cells were used as controls.

\section{Statistical analysis}

A minimum of 300 cells was counted in each sample. Results were expressed as the Mean \pm SE for three independent determinations. Biological activity was the result of one individual experiment, performed in triplicate. Correlation between variables was investigated using a SPSS (Chicago, IL) statistical software package (SPSS for Windows, ver. 17, 2008).

\section{Numerical modelling of effect of electromagnetic field on cancer cells}

To develop a mathematical model capable of accurately predicting the influence of EMF on cancer cells, we used 


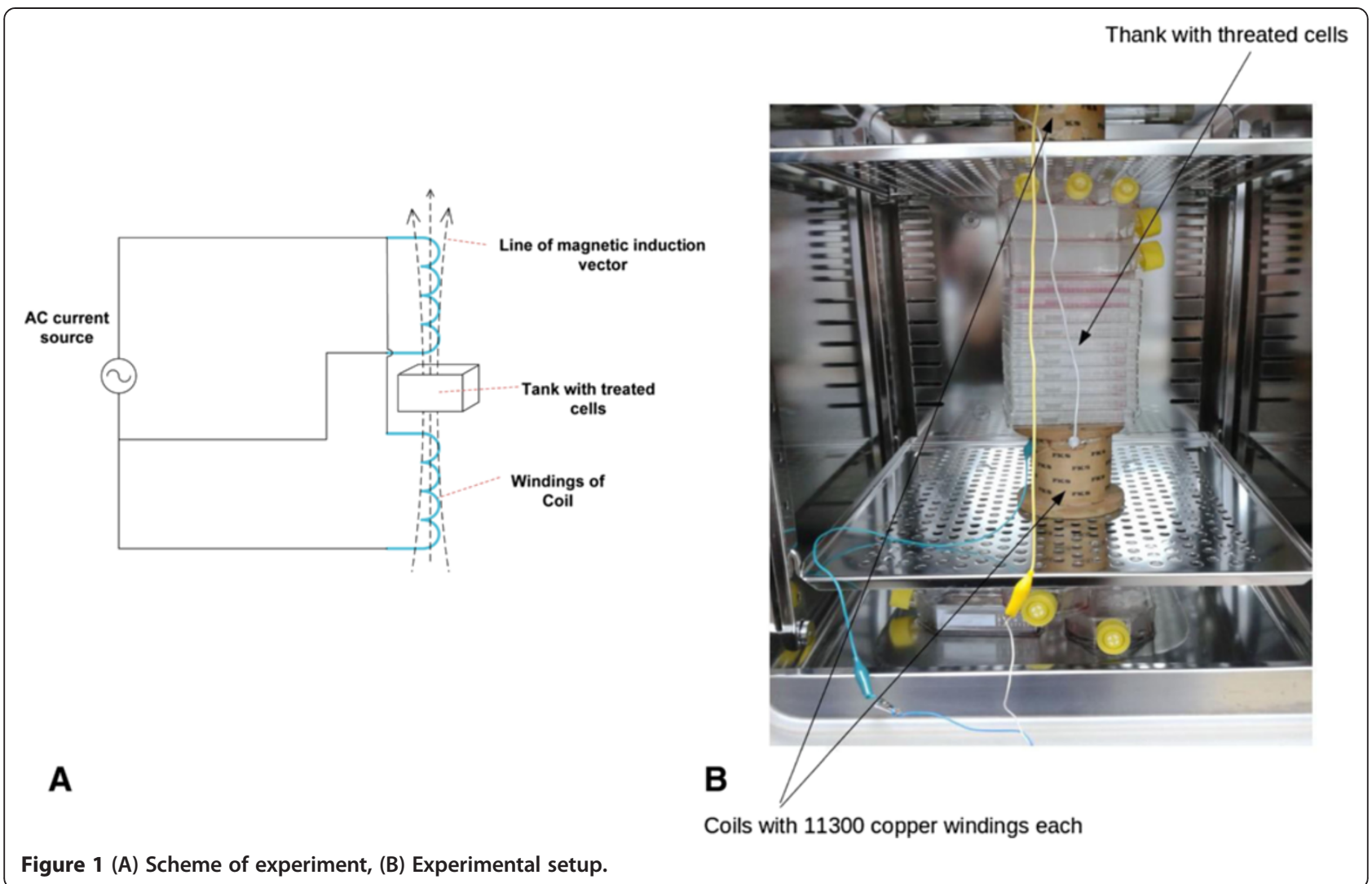

the model proposed by Swanson et al [24], mainly used for brain tumours, but also to model the behaviour of any untreated tumour [25]. Extensions of this model included the effects of radiation therapy [25], resection [26] and chemotherapy [27]. Here, the fundamental model was extended to take into account the effect of EMF.

The basic equation of the extended model is given by:

$$
\frac{\partial \mathbf{c}}{\partial t}=D \frac{\partial^{2} \mathbf{c}}{\partial \mathbf{x}^{2}}+\rho \mathbf{c}-F(t) \mathbf{c}
$$

where $c=c(\mathbf{x}, t)$ is the concentration of tumour cells, $D$ is the spatially constant diffusion coefficient (defining cell migration), $\rho$ is the net rate of cell proliferation and $F(t)$ represents the effect of EMF at time t.

The initial and boundary conditions are set such that at $t=0$ the cell concentration is set to $c_{0}$ and the zero flux is prescribed on the boundary of the observed domain $-\mathbf{n} \cdot \nabla c=0$. In-house developed software was used for imaging analysis of experimental results (images of cells in 96-well plate obtained during the experiment). All the areas of cells visible on experimental images are summed and the cumulative single cell with the same area created, as shown in Figure 2. The initial cell concentration is determined using this software and images from the beginning of the experiment. The same procedure was used to evaluate the percentage of cells over the whole observed domain after $24 \mathrm{~h}$ and $72 \mathrm{~h}$ of cell exposure to EMF. These percentages were later used for parameter estimation.

Since the effect of EMF is represented by an unknown function, it was necessary to estimate the function itself and the parameters. Examining the experimental results, it was concluded that the following logarithmic function would best model the effect of EMF:

$$
F(t)=a \ln (t)+b
$$

where parameters $a$ and $b$ have to be estimated.

Parameters describing the diffusion and proliferation of cancer cells are different for different types of tumours and should be estimated accordingly. Hence, the following parameters need to be estimated using the experimental results - $D, \rho, a$ and $b$. The equation (1) was solved numerically using the finite element method [28]. The in-house developed software for time-dependent twodimensional analysis was used for this purpose. The incremental-iterative form of equation (1) for time step $\Delta t$ and equilibrium iteration " $\mathrm{i}$ " is given by:

$$
\left[\frac{1}{\Delta t} \mathbf{M}_{c}+{ }^{t+\Delta t} \mathbf{K}_{c c}^{(i-1)}\right] \cdot \Delta \mathbf{c}^{(i)}={ }^{t+\Delta t} \mathbf{F}_{c}^{(i-1)}
$$

The index " $t+\Delta t$ " denotes that the quantities in question are calculated at the end of a time step. The matrix $\mathbf{M}_{c}$ is 


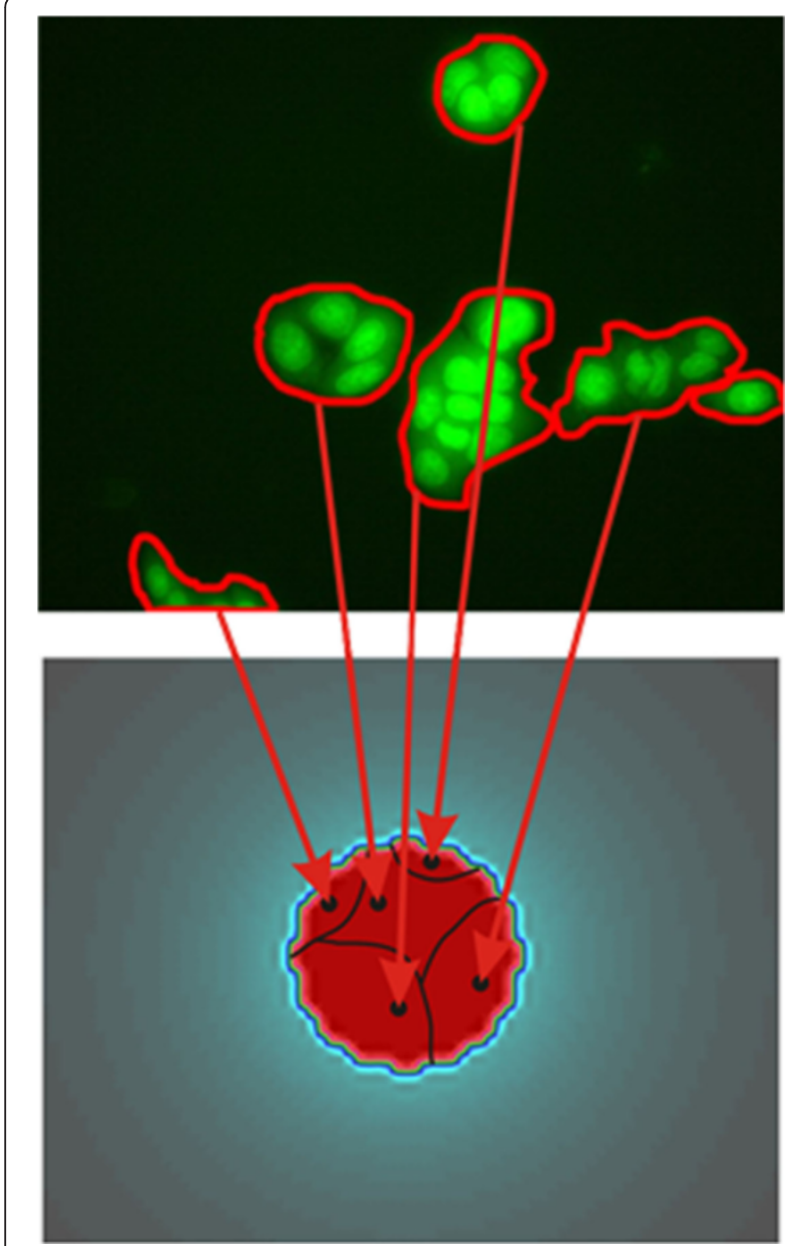

Figure $\mathbf{2}$ The procedure of creation of a single cumulative cell for the numerical model from experimental images. the mass matrix, $\mathbf{K}_{c c}$ is the diffusion matrix (here are also included the effects of electromagnetic field) and $\mathbf{F}_{c}$ is the forcing vector, that takes into account the boundary conditions. The space step for the simulation is $1 \mu m$ and the time step in the simulation is $1 \mathrm{~min}$.

\section{Fitting procedure}

Its aim is to determine diffusion coefficient $\mathrm{D}$, proliferation rate $\rho$ and parameters $a$ and $b$ from the logarithmic function in equation (2). To minimize differences between computer simulations and experiments, we used a hybrid genetic algorithm which combines the power of the genetic algorithm with the speed of the local optimizer. We used a standard genetic algorithm [29] to find the area of the global minimum, then the Nelder-Mead simplex optimization algorithm [30] to take over and find the value of the global minimum.

The best fit minimizes the sum of squared residuals, where residuals represent the differences between experimental and simulation cell area percentages after 24 and
72 hours. We have three experiments with, and three without, the effect of EMF, thus six different functions to minimize, and six sets of parameters to determine. These functions are:

$$
S E=\left(A_{24 h}^{e}-A_{24 h}^{s}\right)^{2}+\left(A_{72 h}^{e}-A_{72 h}^{s}\right)^{2}
$$

where $A_{24 h}^{e}$ and $A_{72 h}^{e}$ are experimental cell area percentages after 24 and 72 hours. $A_{24 h}^{s}$ and $A_{72 h}^{s}$ are cell area percentages obtained with simulation after 24 and 72 hours.

\section{Results and discussion}

\section{Antiproliferative activity}

The difference between the survival of EMF-exposed cells and control cells, as well as the difference between different cell types was observed. The percentages of cell viability after exposure to EMF are given in Figure 3A and B, respectively. The EMF inhibited cell growth in each of the three investigated cell lines, being very similar between the two colon cancer cell lines (88.53\% viable SW480 cells after $24 \mathrm{~h}$, and $94.19 \%$ after $72 \mathrm{~h}$, and $98.28 \%$ viable HCT-116 cells after $24 \mathrm{~h}$, and $97.20 \%$ after $72 \mathrm{~h}$ ). However, the breast cancer cell line MDA-MB-231 was more sensitive to EMF after both investigated exposure times (inhibition $>50 \%$ of MDA-MB-231 cell growth). Only inhibition of the cell growth of treated HCT-116 was not statistically significant in comparison to control HCT-116 cells. Extending the exposure time did not enhance EMF effects. Importantly, higher cell viabilities were observed after $72 \mathrm{~h}$, indicating that EMF had antiproliferative activity which decreased with time.

\section{The results obtained with AO/EB double staining}

To determine the type of cell death induced by EMF in MDA-MB-231, HCT-116 and SW480 cells, the AO/EB method was used. Figure $4(\mathrm{~A})$ and $(\mathrm{C})$ show the intact viable cells (V) and Figure 4(B) and (D) show typical morphological changes after cell exposure to an EM field. After cell exposure to an EMF, cells showed changes in cellular morphology, including reduction in cell volume, chromatin condensation, membrane blebbing, and fragmented nuclei. The AO/EB method was used for differentiation and quantification of viable, apoptotic and necrotic cells. Tables 1 and 2 summarize the results obtained with AO/EB double staining. The percentages of viable, apoptotic and necrotic cells were noted for two incubation periods. Compared with spontaneous apoptosis observed in control cells (Tables 1 and 2), exposure to an EMF resulted in a reduction in the number of viable cells, increased percentages of apoptotic cells in different percentages depending of cell line. Generally, EMF had proapoptotic activity. EMF did not cause necrosis in the investigated colon cancer cell lines 

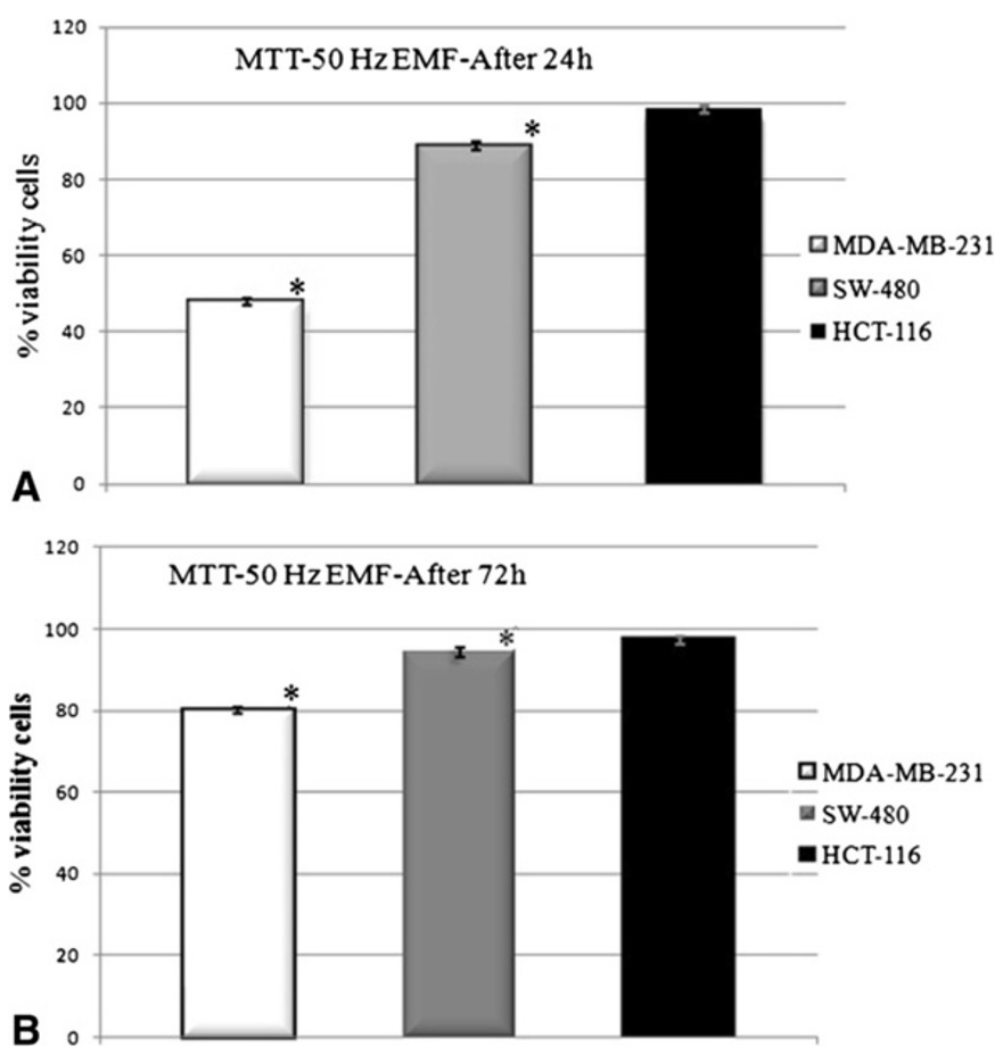

Figure 3 Effects of $50 \mathrm{~Hz}$ EMF on the cancel cell after $\mathbf{2 4 h}$ and $\mathbf{7 2 h}$ of exposure. (A) After $24 \mathrm{~h}$ of exposure. (B) After $72 \mathrm{~h}$ of exposure. The histogram of effects of $50 \mathrm{~Hz}$ EMF on human breast cancer cell line MDA-MB-231 and colon cancer cell lines HCT-116 and SW-480. The antiproliferative effect was measured by MTT assay after $24 \mathrm{~h}$ of exposure. All values are mean $\pm \mathrm{SEM}, \mathrm{n}=3,{ }^{*} p<0.05$ as compared with control (100\%).

or, at the very least, a very small percentage, but it did so in MDA-MB-231 cells (9.68\%).

\section{Results of the fitting procedure}

Results of the fitting procedure from numerical simulation are given in Tables 3 and 4, respectively (coefficients $a$ and $b$ for the influence of EMF do not exist for control cases in Table 3). The estimated diffusion coefficient is very small, which is in accordance with the fact that cells are practically not migrating throughout the domain. Even with an approximation of a single cumulative cell model, computer results seem very promising. Figure 5 shows the diagram of variation of cell percentages over the whole domain with respect to time. The red line represents the control cancer cell line, where no EMF was applied. The blue line represents the cancer cell line with EMF acting on cells. The black line represents the effect of EMF, which was modelled using the logarithmic function described in equation (2). The results obtained are shown for three different states in time above the diagram in Figure 5. These specific moments in time were chosen because the state of cells during experiments was pictured at these moments and those images are also shown in Figure 5.
In an attempt to explore new avenues of cancer research, we focused on a local treatment with EMF. In contrast to most anticancer agents, EMFs are not associated with any meaningful systemic toxicity [29-34]. Furthermore, it was recently shown that EMF may be used clinically, not only as an antiproliferation agent, but also as an effective adjuvant to currently used chemotherapeutic agents.

The aim of this study was to investigate the influence of EMF on three cancer cell lines. The analysis was performed in vitro and by computer simulation. After $24 \mathrm{~h}$ incubation cells were exposed to $50 \mathrm{~Hz}$ radiofrequency EMF using in vitro exposure systems for $24 \mathrm{~h}$ and $72 \mathrm{~h}$. We developed a specific reaction-diffusion model with the net rate of cell proliferation and effect of EMF in time. Also, the fitting procedure for estimation of the computer model parameters was applied.

The disintegration of cells treated by EMF of $50 \mathrm{~Hz}$ frequency compared with untreated control cells was clearly shown. EMF had antiproliferative and proapoptotic activity in varying degrees, depending on the cell lines and time of exposure. The effect can be explained according to two proposed mechanisms [28]: during cytokinesis and during cell division when it interferes with the microtubule spindle polymerization processes. Thus, EMF 


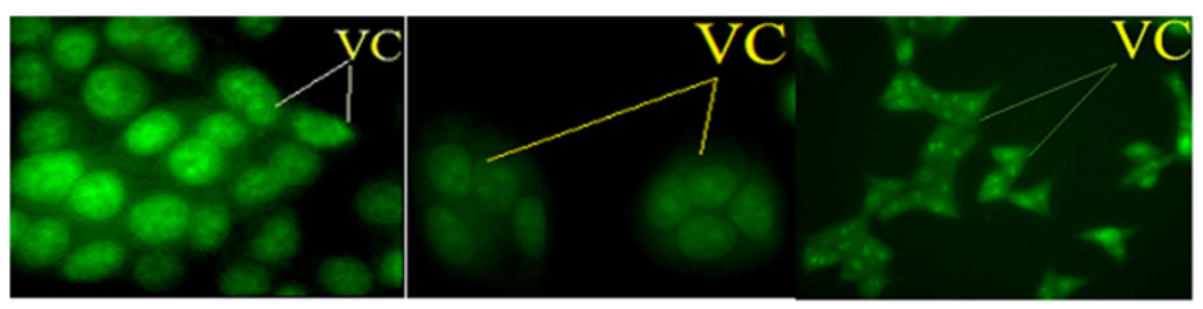

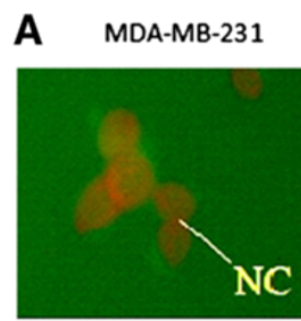

B MDA-MB-231
SW-480

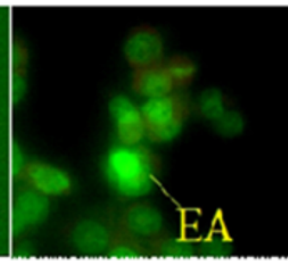

MDA-MB-231

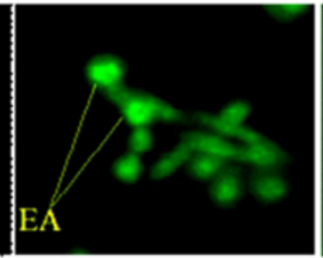

SW-480
HCT-16

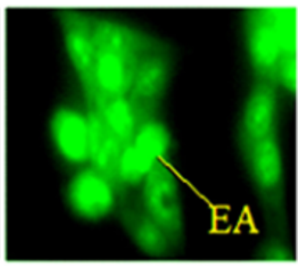

HCT-16
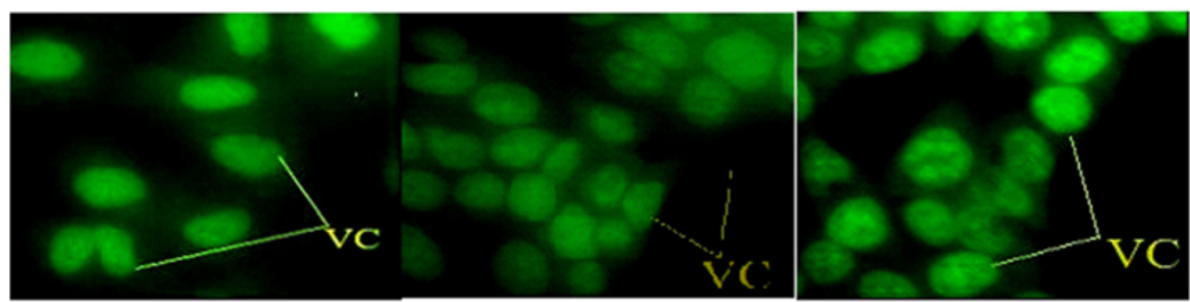

\section{MDA-MB-231}

SW-480

HCT-116
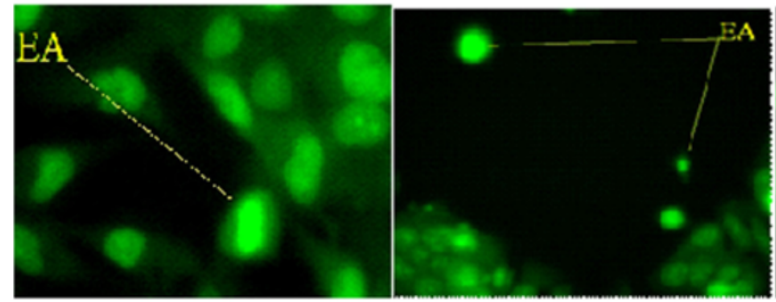

D MDA-MB-231

SW -480

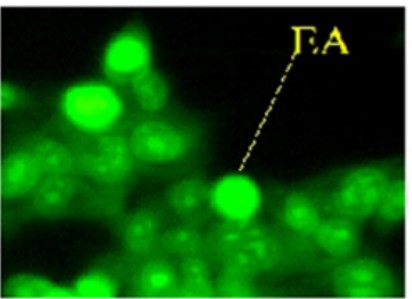

HCT-116

Figure 4 Untreated and treated cancer cells with $50 \mathrm{~Hz}$ EMF after 24 and 72 h. (A) Untreated cells were observed as control. (B) Treated cells of $50 \mathrm{~Hz}$ EMF after $24 \mathrm{~h}$. (C) Untreated cells were observed as control. (D) Treated cells of $50 \mathrm{~Hz}$ EMF after $72 \mathrm{~h}$. AO/EB staining of MDA-MB-231, SW-480 and HCT-116 to detect the type of cell death induced by $50 \mathrm{~Hz}$ EMF. Magnification on fluorescent microscope was 400x. VC-Viable cells; EA-Early apoptotic cells; LA-Late apoptotic cells; NC-Necrotic cells.

Table 1 Effect of $50 \mathrm{~Hz}$ EMF on cell death of human breast cancer cell line MDA-MB-231 and colon cancer cell lines SW-480 and HCT-116 stained with AO/EB and analyzed under a fluorescence microscope after $24 \mathrm{~h}$

\begin{tabular}{lllll}
\hline Cell lines & VC & EA & LA & NC \\
\hline Control MDA-231 & $97,92 \pm 0,24$ & $2,07 \pm 0,46$ & 0 & 0 \\
50 Hz EMF MDA-231 & $87,577 \pm 0,33^{*}$ & $2,705 \pm 0,45$ & $0,278 \pm 0,27$ & \\
Control SW480 & $95,07 \pm 0,25$ & $4,92 \pm 0,25$ & 0 & 0 \\
50 Hz EMF SW480 & $95,428 \pm 0,32$ & $3,266 \pm 0,60$ & $0,130 \pm 0,13$ & $1,168 \pm 0,43$ \\
Control HCT-116 & $93,75 \pm 1,91$ & $6,25 \pm 1,91$ & 0 & 0 \\
50 Hz EMF HCT-116 & $86,948 \pm 1,01^{*}$ & $12,63 \pm 1,59^{*}$ & $0,235 \pm 0,23$ & $0,175 \pm 0,17$ \\
\hline
\end{tabular}

$\mathrm{n}=3,{ }^{*} p<0.05$ as compared with control.

VC-viable cells; EA- early apoptosis; LA-late apoptosis; NC-necrotic cells. 
Table 2 Effect of $50 \mathrm{~Hz}$ EMF on cell death of human breast cancer cell line MDA-MB-231 and colon cancer cell lines SW-480 and HCT-116 stained with AO/EB and analyzed under a fluorescence microscope after $72 \mathrm{~h}$

\begin{tabular}{lllll}
\hline Cell lines & VC & EA & LA & NC \\
\hline Control MDA-231 & $95,74 \pm 0,60$ & $4,25 \pm 0,60$ & 0 & 0 \\
50 Hz EMF MDA-231 & $94,05 \pm 1,39^{*}$ & $5,63 \pm 1,39^{*}$ & 0 & 0 \\
Control SW-480 & $94,05 \pm 0,07$ & $5,95 \pm 0,07$ & 0 & 0 \\
50 Hz EMF SW-480 & $80,459 \pm 1,83^{*}$ & $18,99 \pm 1,29^{*}$ & $0,46 \pm 0,175$ & $0,075 \pm 0,075$ \\
Control HCT-116 & $96,38 \pm 3,31$ & $3,62 \pm 0.23$ & 0 & 0 \\
50 Hz EMF HCT-116 & $94,16 \pm 1,19^{*}$ & $5,82 \pm 1,19^{*}$ & 0 \\
\hline
\end{tabular}

$\mathrm{n}=3,{ }^{*} p<0.05$ as compared with control.

VC-viable cells; EA- early apoptosis; LA-late apoptosis; NC-necrotic cells.

disrupts the cell structure, inhibits cell division and results in cell death.

These results add to the existing knowledge in this field. Following encouraging in vitro and in vivo results [9], Kirson et al [10] used alternating EMFs in 10 patients with recurrent glioblastoma multiforme. The median time to disease progression was 26.1 weeks (range, 3-124 weeks) and the progression-free survival time at 6 months was $50 \%$. The median overall survival time (MST) was 62.2 weeks at the time of the report (range, 20.3-124 weeks), seemingly an improvement which was more than double when compared to historic controls. No serious adverse events (SAE) were observed, while 9 out of 10 patients experienced mild to moderate (grade 1 and 2, respectively) contact dermatitis beneath the electrode gel, all successfully treated with topical steroid creams and periodic electrode relocation.

In an interesting approach, Barbault et al [12] tried to identify tumour-specific frequencies in patients with advanced cancer using a non-invasive biofeedback method to identify such tumour-specific frequencies. In 163 examined patients, a total of 1524 frequencies ranging from $0.1 \mathrm{~Hz}$ to $114 \mathrm{KHz}$ were identified. Most frequencies (57-92\%) were specific for a single tumour type. Self-administered treatment, three times a day, was offered to 28 patients (26 treated in Switzerland and 2 in Brazil). Thirteen patients were evaluated for response.

Table 3 Fitted values of $D, \rho, a$ and $b$

\begin{tabular}{lllll}
\hline Cell lines & $\boldsymbol{D}$ & $\boldsymbol{\rho}$ & $\boldsymbol{a}$ & $\boldsymbol{b}$ \\
\hline HCT & 0.00769 & 0.09412 & 0.0069 & 0.0670 \\
MDA & 0.00149 & 0.08876 & 0.0067 & 0.0652 \\
SW & 0.00014 & 0.11498 & 0.0100 & 0.0863 \\
Control HCT & 0.01665 & 0.00914 & & \\
Control MDA & 0.00633 & 0.00785 & & \\
Control SW & 0.00606 & 0.00421 & & \\
\hline
\end{tabular}

$D=$ diffusion coefficient; $\rho=$ proliferation rate; $a$ and $b=$ parameters from the logarithmic function in eq. (2).
Both patients with hormone-refractory metastatic breast cancer achieved either a complete response (lasting 11 months), or a partial response (lasting 13.5 months). Four patients had stable disease (SD) (range 4.0 to $>34.1$ months), while only one patient experienced grade 1 fatigue.

The largest study so far has been published by Costa et al [19] with 41 patients having advanced hepatocellular carcinoma treated with low levels of EMF modulated at specific frequencies $(27.12 \mathrm{MHz})$. Three-daily outpatient treatments were administered until disease progression or death. The majority of these patients had either failed standard treatment options or had severely impaired liver function that limited their ability to tolerate any form of systemic or intrahepatic therapy. Fourteen $(34.1 \%)$ patients had SD for $>6$ months. Median progression-free survival was 4.4 months and MST was 6.7 months, with no grade 2-5 treatment-related toxicities observed. This data seems comparable to recent data from other therapies in this setting [14].

Having a long lasting interest in computer modelling, we have developed a model that intends to simulate the influence of EMF on cancer cells. The images of experimental setup were used to create a cumulative single cell for computer simulation. In our approximation, we achieved very good comparison with the in vitro results. However, any computer model used in the clinic must precisely predict tumour size and shape. Future computer models, too, have to predict the changes induced in the host by the growing tumour, and the impact that one or multiple treatment strategies could have on halting tumour progression. Also probably patient specific EMF frequency could be optimised through computer simulation. We choose extremely low frequency $50 \mathrm{~Hz}$ from literature $[13,35]$ but further research should go in the direction of investigation more frequencies. In addition, we would like to emphasize that the evidence from (only) two different cancer cell lines may well not be enough to infer to conclusions about the effect of EMF in cancer. We plan to use current study findings to 
Table 4 Comparison between experimental and computer simulation results

\begin{tabular}{|c|c|c|c|c|c|}
\hline \multirow[t]{2}{*}{ Cell lines } & \multicolumn{2}{|l|}{$24 \mathrm{~h}$} & \multicolumn{2}{|l|}{$72 \mathrm{~h}$} & \multirow{2}{*}{$\begin{array}{l}\text { Squared } \\
\text { error } \\
\text { (SE) }\end{array}$} \\
\hline & Experimental $\left(A_{24 h}^{e}\right)$ & Simulation $\left(A_{24 h}^{s}\right)$ & Experimental $\left(A_{72 h}^{e}\right)$ & Simulation $\left(A_{72 h}^{s}\right)$ & \\
\hline$\overline{\mathrm{HCT}}$ & 0.36301 & 0.49453 & 0.39287 & 0.38828 & 0.01731 \\
\hline MDA & 0.17442 & 0.22891 & 0.18731 & 0.18828 & 0.00297 \\
\hline SW & 0.14670 & 0.15703 & 0.12372 & 0.12266 & 0.00010 \\
\hline Control HCT & 0.38432 & 0.37578 & 0.37731 & 0.37812 & $7.3 \times 10^{-5}$ \\
\hline Control MDA & 0.15823 & 0.16641 & 0.15470 & 0.15391 & $6.7 \times 10^{-5}$ \\
\hline Control SW & 0.29761 & 0.30078 & 0.27990 & 0.27891 & 0.00001 \\
\hline
\end{tabular}

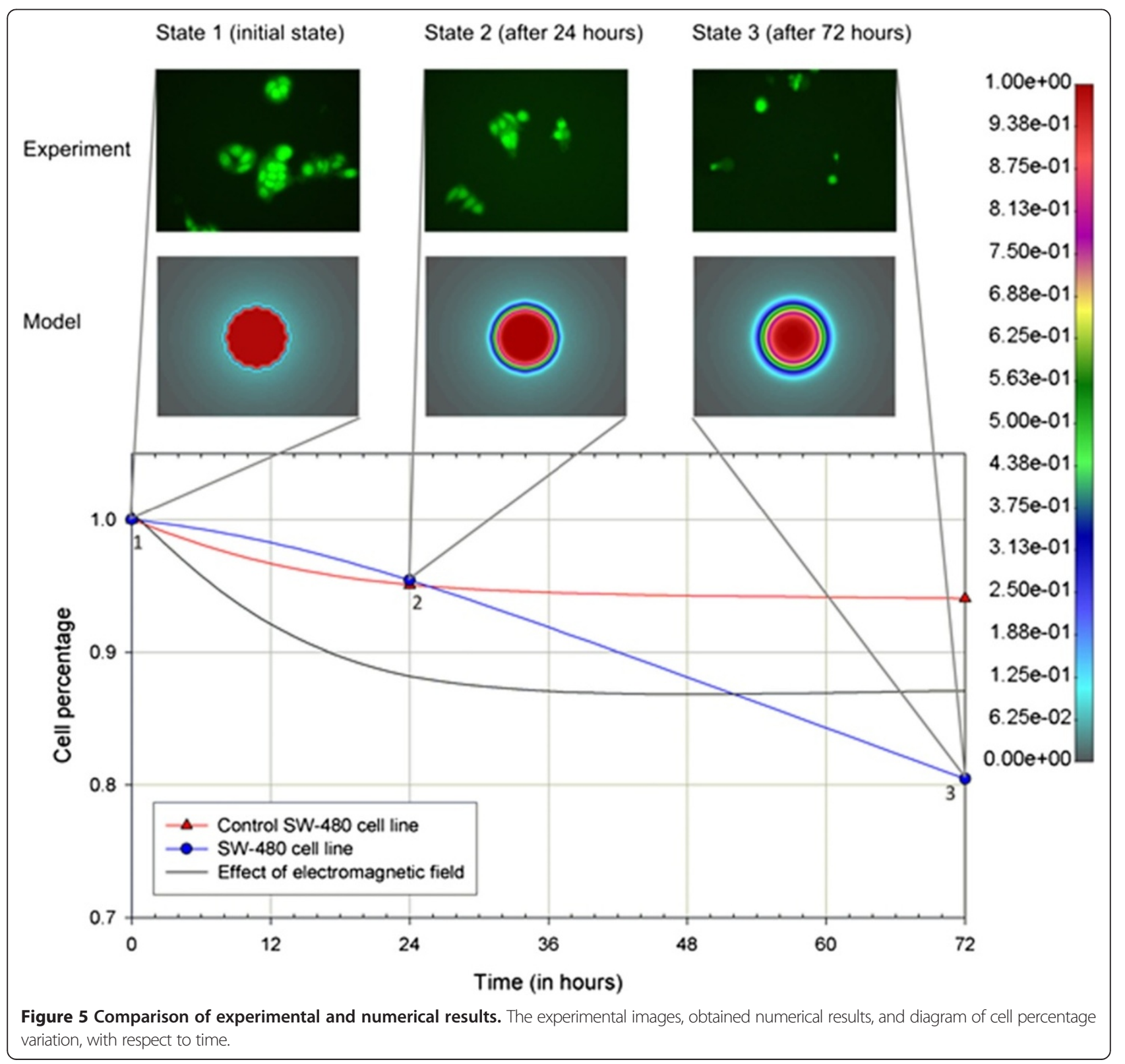


upgrade future experiments by addressing two major pathways: one, by considering a certain class of cancers, modulated by the same genes, and two, by using several cell lines, belonging to the same cancer. In the first case, one could prove that EMF may be useful for "similar cancers", while in the second case one could prove that a specific cancer could be affected by EMF. Based on findings, further in vivo studies would be needed as to bridge the gap towards initial clinical use, by, hopefully, identifying those cancers which may be good target groups in this setting.

Results in the current study had been obtained with the use of EMF alone. It is, however, interesting to observe that additional anticancer treatment, namely chemotherapy, can also be added in order to improve treatment results in clinic due to possible synergistic effects. EMF in combination with various chemotherapeutic and targeted agents demonstrated no increase in side effects clinically, while similar findings were reported in vitro $[12,36]$. Other treatment modalities such as magnetic nano-particles, ultrasound, and/or radiotherapy [37,38]. Of particular importance is the finding of the recent phase III study [39] in recurrent glioblastoma multiforme which showed efficacy similar to the standard chemotherapy regimen but with fewer adverse effects [39]. The use of similar devices are eagerly awaited to be tested in a number of tumor sites.

\section{Conclusion}

Findings of the current study seem to reconfirm potential application of EMF in oncology. Computer simulation tools also uncover a new avenue to optimize control of tumour growth and may have broad implications for the treatment of cancer. These results call for additional investigations before being tested in a phase I-II clinical trial.

\section{Competing interests}

All authors in this manuscript declare that NO financial and non-financial competing interests exist.

\section{Authors' contributions}

NF, TD, MR carried out simulation/modelling studies. DC, MC, SM, AP carried out in vitro experimental studies. NF, SM participated in the design of the study and helped to draft the manuscript. BJ participated in the design of the study and drafted a manuscript. All authors read and approved the final manuscript.

\section{Acknowledgments \\ Funded by the Serbian Ministry of Education, Science and Technological Development grants: I||41007 and II141010. \\ The Funding body did not play any role in the design, collection, analysis, and interpretation of data; in the writing of the manuscript; and in the decision to submit the manuscript for publication.}

\section{Author details}

${ }^{1}$ Faculty of Engineering, University of Kragujevac, Sestre Janjica 6, 34000 Kragujevac, Serbia. ${ }^{2}$ Harvard University, Boston, USA. ${ }^{3}$ BioIRC Bioengineering R\&D Center, Kragujevac, Serbia. ${ }^{4}$ Laboratory for cell \& molecular biology, Faculty of Science, University of Kragujevac, Kragujevac, Serbia. ${ }^{5}$ Institute of Pulmonary Diseases, Sremska Kamenica, Serbia.
Received: 21 May 2014 Accepted: 11 August 2014

Published: 22 August 2014

\section{References}

1. Polk C: Therapeutic applications of low-frequency sinusoidal and pulsed electric and magnetic fields. In The Biomedical Engineering Handbook. Edited by Bronzino JD. Boca Raton, FL: CRC Press; 1995:1404-1406.

2. Palti $Y$ : Stimulation of internal organs by means of externally applied electrodes. J Appl Physiol 1966, 21:1619-1623.

3. Besset CA: The development and application of pulsed electromagnetic fields (PEMFs) for ununited fractures and arthrodeses. Clin Plast Surg 1985, 12:259-277.

4. Chou CK: Radiofrequency hyperthermia in cancer therapy. In The Biomedical Engineering Handbook. Edited by Bronzino JD. Boca Raton, FL: CRC Press; 1995:1424-1430.

5. Elson E: Biologic effects of radiofrequency and microwave fields in vivo and in vitro experimental results. In The Biomedical Engineering Handbook. Edited by Bronzino JD. Boca Raton, FL: CRC Press; 1995:1417-1423.

6. Zimmerman U, Vienken J, Piwat G: Rotation of cells in an alternating electric field: the occurrence of a resonance frequency. Z Naturforsch C 1981, 36:173-177.

7. Holzapfel C, Vienken J, Zimmermann U: Rotation of cells in an alternating electric field: theory and experimental proof. J Membr Biol 1982, 67:13-26.

8. Pawlowski P, Szutowicz I, Marszalek P, Fikus M: Bioelectrorheological model of the cell. 5. Electrodestruction of the cellular membrane in alternating electrical field. Biophys J 1993, 65:541-549.

9. Kirson ED, Gurvich Z, Schneiderman R, Dekel E, Itzakhi A, Wasserman Y: Disruption of cancer cell replication by alternating electric fields. Cancer Res 2004, 64:3288-3295.

10. Kirson ED, Dbaly V, Tovarys F, Vymazal J, Soustiel JF, Itzakhi A: Alternating electric fields arrest cell proliferation in animal tumor models and human brain tumors. Proc Natl Acad Sci 2007, 104:10152-10157.

11. Zimmerman JW, Pennison MJ, Brezovich I, Yi N, Yang CT, Ramaker R: Cancer cell proliferation is inhibited by specific modulation frequencies. $\mathrm{Br} J$ Cancer 2012, 106:307-313.

12. Barbault A, Costa FP, Bottger B, Munden RF, Bomholt F, Kuster N: Amplitude-modulated electromagnetic fields for the treatment of cancer: discovery of tumor-specific frequencies and assessment of a novel therapeutic approach. J Exper Clin Cancer Res 2009, 28:51.

13. Zimmerman JW, Jimenez H, Pennison MJ, Brezovich I, Morgan D, Mudry A, Costa FP, Barbault A, Pasche B: Targeted treatment of cancer with radiofrequency electromagnetic fields amplitude-modulated at tumor-specific frequencies. Chin J Cancer 2013, 32:573-581.

14. Fang $M$, Zhang HQ, Xue SB: Role of Calcium in apoptosis of $\mathrm{HL}-60$ cells induced by harring tonine. Science in China, Ser C 1998, 41:600-607.

15. Silva CP, Oliveira CR, Lima MCP: Apoptosis as a mechanism of cell death induced by different chemotherapeutic drugs in human leukemic T-lymphocytes. Biochem Pharmacol 1996, 51:1331-1340.

16. Zhang X, Zhang H, Zheng C, LI C, Zhang X, Xiong W: Extremely Low Frequency (ELF) pulsed-gradient magnetic fields inhibit malignant tumour growth at different biological levels. Cell Biol Int 2002, 26:599-603.

17. Harris PA, Lamb J, Heaton B, Wheatley DN: Possible attenuation of the G2 DNA damage cell cycle checkpoint in HeLa cells by extremely low frequency (ELF) electromagnetic fields. Cancer Cell Int 2002, 2:3.

18. Cameron IL, Sun LZ, Short N, Hardman WE, Williams CD: Therapeutic Electromagnetic Field (TEMF) and gamma irradiation on human breast cancer xenograft growth, angiogenesis and metastasis. Cancer Cell Int 2005, 5:23. doi:10.1186/1475-2867-5-23.

19. Costa FP, de Oliveira AC, Meirelles R, Machado MCC, Zanesco T, Surjan R, Chammas MC, de Souza RM, Morgan D, Cantor A, Zimmerman J, Brezovich I, Kuster N, Barbault A, Pasche B: Treatment of advanced hepatocellular carcinoma with very low levels of amplitude-modulated electromagnetic fields. Br J Cancer 2011, 105:640-648.

20. Gevertz JL, Gillies GT, Torquato S: Simulating tumor growth in confined heterogeneous environments. Phys Biol 2008, 5:036010.

21. Mosmann T: Rapid colorimetric assay for cellular growth and survival: application to proliferation and cytotoxicity assays. J Immunol Meth 1983, 65:55-63.

22. Baskić D, Popović S, Ristić P, Arsenijević NN: Analysis of cycloheximide-induced apoptosis in human leukocytes: fluorescence microscopy using annexin V/ 
propidium iodide versus acridin orange/ethidium bromide. Cell Biol Int 2006, 30:924-932.

23. Yu Q, Liu Y, Wang C, Sun D, Yang X, Liu Y, Liu J: Chiral Ruthenium(II) polypyridyl complexes: stabilization of g-quadruplex DNA, inhibition of telomerase activity and cellular uptake. PLoS One 2012, 7(12):e50902. doi:10.1371/journal.pone.0050902.

24. Swanson KR, Brigde C, Murray JD, Ellsworth AC Jr: Virtual and real brain tumors: using mathematical modeling to quantify glioma growth and invasion. J Neurol Sci 2003, 216:1-10.

25. Rockne R, Alvord EC Jr, Rockhill JK, Swanson KR: A mathematical model for brain tumor response to radiation therapy. J Math Biol 2009, 58:561-578.

26. Woodward DE, Cook J, Tracqui P, Cruywagen GC, Murray JD, Alvord EC Jr: A mathematical model of glioma growth: the effect of extent of surgical resection. Cell Prolif 1996, 29:269-288.

27. Tracqui P, Cruywagen GC, Woodward DE, Bartoo GT, Murray JD, Alvord EC Jr. A mathematical model of glioma growth: the effect of chemotherapy on spatio-temporal growth. Cell Prolif 1995, 28:17-31.

28. Filipovic N, Peulic A, Zdravkovic N, Grbovic-Markovic V, Jurisic-Skevin A: Transient finite element modeling of functional electrical stimulation. Gen Physiol Biophys 2011, 30:59-65.

29. Holland JH: Adaptation in Natural and Artificial Systems. Ann Arbor: University of Michigan Press; 1975.

30. Nelder J, Mead R: A simplex method for function minimization. Comput $J$ 1965, 7:308-313.

31. Kirson ED, Schneiderman RS, Dbaly V, Tovarys F, Vymazal J, Itzhaki A: Chemotherapeutic treatment efficacy and sensitivity are increased by adjuvant alternating electric fields (TTFields). BMC Med Phys 2009, 9:1-13.

32. Salzberg $M$, Kirson E, Palti $Y$, Rochlitz C: A pilot study with very low intensity, intermediate-frequency electric fields in patients with locally advanced and/or metastatic solid tumors. Onkologie 2008, 31:362-365.

33. Kirson ED, Giladi M, Gurvich Z, Itzhaki A, Mordechovich D, Schneiderman RS: Alternating electric fields (TTFields) inhibitmetastatic spread of solid tumors to the lungs. Clin Exp Metastasis 2009, 26:633-640.

34. Schneiderman RS, Shmueli E, Kirson ED, Palti Y: TTFields alone and in combination with chemotherapeutic agents effectively reduce the viability of MDR cell sub-lines that overexpress $A B C$ transporters. BMC Cancer 2010, 10:229.

35. Kaszuba-Zwoinska J, Wojcik K, Bereta M, Ziomber A, Pierzchalski P, Rokita E, Marcinkiewicz J, Zaraska W, Thor P: Pulsating electromagnetic field stimulation prevents cell death of puromycin treated u937 cell line. J Physiol Pharmacol 2010, 61(2):201-205.

36. Watson JM, Parrish EA, Rinehart CA: Selective potentiation of gynecologic cancer cell growth in vitro by electromagnetic fields. Gynecol Oncol 1998, 71:64-71.

37. Saliev T, Tachibana K, Bulanin D, Mikhalovsky S, Whitby RD: Bio-effects of non-ionizing electromagnetic fields in context of cancer therapy. Front Biosci (Elite Ed) 2014, 6:175-184.

38. Artacho-Cordón F, Salinas-Asensio Mdel M, Calvente I, Ríos-Arrabal S, León J, Román-Marinetto E, Olea N, Núñez Ml: Could radiotherapy effectiveness be enhanced by electromagnetic field treatment? Int J Mol Sci 2013, 14:14974-14995.

39. Stupp R, Wong ET, Kanner AA, Steinberg D, Engelhard H, Heidecke V, Kirson ED, Taillibert S, Liebermann F, Dbalý V, Ram Z, Villano JL, Rainov N, Weinberg U, Schiff D, Kunschner L, Raizer J, Honnorat J, Sloan A, Malkin M, Landolfi JC, Payer F, Mehdorn M, Weil RJ, Pannullo SC, Westphal M, Smrcka M, Chin L, Kostron $H$, Hofer $S$, et al: Novottf-100a versus physician's choice chemotherapy in recurrent glioblastoma: a randomised phase III trial of a novel treatment modality. Eur J Cancer 2012, 48:2192-2202.

doi:10.1186/s12935-014-0084-x

Cite this article as: Filipovic et al:: Electromagnetic field investigation on different cancer cell lines. Cancer Cell International 2014 14:84.

\section{Submit your next manuscript to BioMed Central and take full advantage of:}

- Convenient online submission

- Thorough peer review

- No space constraints or color figure charges

- Immediate publication on acceptance

- Inclusion in PubMed, CAS, Scopus and Google Scholar

- Research which is freely available for redistribution

Submit your manuscript at www.biomedcentral.com/submit
Ciomed Central 